\author{
<Danielle Allard*, Shawna Ferris**, Kiera Ladner**, Carmen Miedema**> \\ $<*$ University of Alberta $><$ Edmonton, Alberta, Canada $>$ \\ $<* *$ University of Manitoba $>$ Winnipeg, Manitoba, Canada $>$
}

\title{
DIGITAL DECOLONIZATION AND ACTIVIST TAGGING IN THE POST-APOLOGY RESIDENTIAL SCHOOL DATABASE (Paper)
}

\begin{abstract}
:
The Post-apology Residential School Database, or PARSD, is a collection of digital and digitized news media responses to and representations of Indian Residential Schools since the Canadian government's official apology in Parliament on June $11^{\text {th }}, 2008$. In this conceptual paper, we discuss PARSD tagging practices, describing how our archival description approach is informed by feminist and anti-colonial theoretical frameworks and outlining how project members and 'guest taggers' describe, organize, and display PARSD records to promote decolonization. We conclude by considering both the potential and possible limitations that these practices may play in decolonizing and reconciling research.
\end{abstract}

\section{Introduction}

The Digital Archives and Marginalized Communities Project, or DAMC, is an interdisciplinary anti-colonial anti-violence activist initiative to research, design, and develop three separate but related digital activist archives in partnership with stakeholder groups. In doing so, DAMC researchers investigate how we and the communities with whom we partner can adopt digital information platforms and systems to reflect community-derived epistemologies, ontologies, and social justice objectives. One of the DAMC digital activist archives is the Post-apology Residential School Database, or PARSD, a collection of digital and digitized news media responses to and representations of Indian Residential Schools since the Canadian government's official apology for Indian Residential Schools in Parliament on June $11^{\text {th }}, 2008$. In this conceptual paper, we discuss PARSD tagging practices, describing how our archival description approach is informed by feminist and anti-colonial theoretical frameworks and outlining how project team members and 'guest taggers' describe, organize, and display PARSD records to promote decolonization. Elsewhere we have argued that record description and descriptors such as tags, are not only tools to facilitate item retrieval but are themselves community produced records, both creating and disrupting complex relationships among archival records in a given archive (Allard, Ferris, Bak \& Ladner, 2015). Here we conclude by considering both the potential and possible limitations that this form of co-created record (in this case tags) may play in decolonizing and reconciling research.

Overarching objectives for the DAMC research project are: to create and mobilize knowledge that contests and re-envisions conceptions of violence against certain people as normal; to build bridges and dialogue between academic and non-academic stakeholder communities; and in 
doing so, to create community-based archives that preserve collaboratively-identified knowledges and histories. Set to go public in summer of 2018, the objectives of PARSD include: to fill a gap in the Truth and Reconciliation Commission of Canada collections by preserving news records about Indian Residential Schools (IRS); to encourage education about IRS, decolonization, critical engagement, healing, and reconciliation; and to assist in tracking ongoing intergenerational effects of colonization. In addition to PARSD, other archives within the DAMC are the Missing and Murdered Indigenous Women Database (MMIWD) and the Sex Work Database (SWD). While each DAMC collection is unique and contains records within it that have been identified by community partners as critical to their own histories, a shared feature of all DAMC archives is a Canadian news media collection relevant to their particular focus. Early in the project's development, we determined that each archive should maintain a record of the often dehumanizing ways Indigenous and other marginalized groups are described on our public record and in public spaces. At present, PARSD is solely a media archive that collects Indigenous and non-Indigenous (or mainstream) Canadian news media about Indian Residential Schools in Canada.

\section{Connecting decolonizing and feminist theory to archival practice}

Common to research approaches in Archival Studies, this conceptual paper interrogates the relationship between our archival practice and the theoretical frameworks that inform it. We discuss the relationship between our tagging practices and the feminist and anti-colonial frameworks that both anchor the practice and justify the intended outcomes of the project. PARSD tagging practices are used as a case example to think through how feminist and decolonizing praxis might shape participatory descriptive practices within archival settings.

The Canadian Truth and Reconciliation Commission (TRC) Calls to Action speak directly to settler colonial archival institutions within Canada, calling on them to play a leading role in reconciliation (2012). As the calls suggest, archives can and must play a role in such reconciling research, in truth-telling, and in holding institutions (such as government, archives themselves, and media) and settler society to account. More than this, Indigenist archives must centre Indigenous knowledges, histories, and intellectual traditions (Ghaddar, 2016; McKemmish, Faulkhead, \& Russell, 2011; Ross, McKemmish, \& Faulkhead, 2006; Thorpe, 2017). In this context, "Indigenous knowledges," or bodies of knowledge possessed by certain social groups "associated with the long-term occupancy of a certain place" and built cumulatively "through both historical and current experience" (Dei, Hall, \& Rosenberg, 2000), operate as counternarratives. Indeed, central to the PARSD project is the understanding of such knowledges as "a rich social depot, which can bring about social justice in a variety of cultural contexts" (Shahjahan, 2005, p. 214). These counter-narratives can, for example, re-introduce Indigenous (hi)stories and understandings of events, spaces, places, and relationships and, in doing so, disseminate decolonizing knowledge and actual, non-assimilative reconciliation. This work is also situated broadly within a framework that supports Indigenous data sovereignty and considers how Indigenous communities must retain rights and stewardship over their knowledges and data (First Nations Information Governance Centre, 2018; Kukutai \& Taylor, 2016).

The PARSD project engages in decolonizing research that explicitly and deliberately empowers both academic researchers, archivists, and communities as partners in the research process by cocreating archival records drawing from community members' individual and shared experiences 
and memories, shared oral (hi)stories, and in community spaces and geographies. More specifically, PARSD interrogates, exposes, and re-casts the relationships between oppressive and decolonizing knowledges through the foregrounding and privileging of tags that represent community based knowledges and languages.

Our dual approach to tagging includes developing a controlled vocabulary by project archivists and researchers, what we are calling "baseline tags"; we also work with "guest taggers" to facilitate their development of a naturally emerging folksonomy. Baseline descriptive tagging was recently concluded by archivists on the project. At present all tags appear in the English language though we continue to work with community members to explore the possibility of adding Indigenous languages to our baseline tags. This is being followed by inviting and paying community members or "guest taggers" to each tag a set of self-selected news stories. Taggers will receive some basic training about tagging and archival description but for the most part, will be left to their own devices to tag articles with the terms that they deem appropriate in whatever language they so choose. As part of the process, they will be asked to document why they selected the tags that they did. Guest taggers will include Indigenous academics, activists, artists, and community members including previous students from Indian Residential Schools and the children of such students. Taggers will span all ages and genders. Each tagger will also provide us with a brief biography of themselves to be included in the archive and to which all of the tags they generate will be linked.

This approach will put taggers' folksonomies both in conversation with mainstream news and in conversation with each other. We imagine using visualization tools such as tag clouds or maps to demonstrate how tags were used, what tags were most frequently used, and where there is significant dissent both between individual and baseline tags. This approach will allow a more traditional folksonomy to emerge from the database that includes all of the idiosyncrasies, inconsistencies, and complexities that are inherent and so interesting in such systems. More than this, guest taggers will inform and help frame our future analytical pathways through PARSD records and facilitate further intergenerational dialogue and analysis about/around these representations.

\section{Discussion}

While we don't know what tags guest taggers will use and how they will select and make sense of the news articles they choose to tag, we articulate here a tagging process intended to interrupt practices of archival description that can re-inscribe rather than disrupt colonial narratives.

PARSD uses Indigenous knowledges to reframe colonial records and promote decolonization. In doing so, we endeavor to develop a publicly accessible digital resource that intervenes in ongoing mainstream representations of Canada as post-colonial. We work, too, to resist representations that frame healing and reconciliation between Indigenous nations and settler Canadians (both individual and governmental) as inevitable, or as a 'great big hug', to be easily achieved through an 'acknowledgement of territory' on Canada Day or by including Indigenous peoples as a teaching topic of Canadian history (Ladner \& Tait, 2017). As the lessons of PARSD make very clear, such representations obfuscate the well-documented ongoing effects of colonization in Canada. Genuine decolonization de-centres the privileged position of settlers' voices (in this case mainstream news reporting), and requires full acknowledgement of past and 
present colonial violence as well as prolonged effort to understand and undo colonial ignorance and erasures of Indigenous knowledges, histories, and peoples.

We conclude however by asking ourselves a difficult question. While we recognize that a myriad of archival practices have a role to play in working towards decolonization, nonetheless we ask ourselves how far this archive can take us, given that we are reframing colonial records and thus must first centre mainstream news records in order to de-centre them? This process does not envision entirely new frameworks, conversations, and collections. PARSD allows us to remember the past but does it allow us to imagine what reconciliation might actually be? Even as we imagine tags to be complex and alternative records that recast mainstream archival records, can they actually de-centre these particular representations of the past?

\section{Reference List:}

Allard, D., Ferris. S., Bak, G, \& Ladner, K. (2015). The tag is the record: Creating and deploying tagging folksonomies in DAMC. Presented at the Community Informatics Research Network conference, Prato, Italy, November 10, 2015.

Dei, G., Hall, B., \& Rosenberg, D. (2000). Indigenous Knowledges in Global Contexts: Multiple Readings of Our World. Toronto: University of Toronto Press.

First Nations Information Governance Centre. (2018). Ownership. Control. Access and Possession. Retrieved from http://fnigc.ca/ocap.html

Ghaddar, J. (2016). The spectre in the archive: Truth, reconciliation, and Indigenous archival memory. Archivaria, 82, 3-26.

Kukutai, T. \& Taylor, J. (2016). Indigenous data sovereignty: Towards an agenda. Acton: ANU Press.

Ladner, K. \& Tait, M. (Eds.) (2017). Surviving Canada: Indigenous Peoples Celebrate 150 Years of Betrayal. Winnipeg: ARP Books.

McKemmish, S., Faulkhead, S., \& Russell, L. (2011). Distrust in the archive: Reconciling research. Archival Science, 11, 211-239.

Ross, F., McKemmish, S. \& Faulkhead, S. (2006). Indigenous knowledge and the archives: Designing trusted archival systems for Koorie communities. in Archives \& Manuscripts, 34(2), 112-151.

Shahjahan, R. (2005). Mapping the field of anti-colonial discourse to understand issues of Indigenous knowledges: Decolonizing praxis. McGill Journal of Education, 40(2), 213-240. 
Thorpe, K. (2017). Aboriginal community archives: A case studies in ethical community research. In Anne J. Gilliland, Sue McKemmish, \& Andrew J. Lau (Eds.) Research in the archival multiverse. AUS: Monash University Publishing.

Truth and Reconciliation Commission of Canada. (2012). Truth and Reconciliation Commission of Canada: Calls to Action. Winnipeg: Truth and Reconciliation Commission of Canada. 